\title{
Delayed Ureterectomy after Incomplete Nephroureterec- tomy for Upper Tract Urothelial Carcinoma: Pathologic Findings and Outcomes
}

\author{
E. Jason Abel, Mark B. Fisher, Surena F. Matin, Ashish M. Kamat, Colin P. Dinney, H. Barton Grossman \\ Department of Urology, Anderson Cancer Center, University of Texas, TX, USA
}

\section{ABSTRACT}

Objectives: To evaluate the pathologic findings and outcomes after distal ureterectomy for a retained ureteral segment following incomplete nephroureterectomy for urothelial carcinoma of the renal pelvis or ureter.

Materials and Methods: After IRB approval, an institutional database identified patients who underwent distal ureterectomy for a retained ureteral segment after assumed complete nephroureterectomy for urothelial carcinoma of the upper ureter or renal pelvis. Clinical and pathologic variables were analyzed.

Results: From January 1993 to July 2007, 12 patients were identified with median age at the time of ureterectomy of 60.5 years (41-85 years). Initial approach to surgery was open in 9 patients and laparoscopic in 3 patients. The median time from nephroureterectomy to distal ureterectomy was 23.5 months (range 2-66).

At the time of initial surgery, pathologic stage was Ta, T1, T2, and T3 in 3,4,1, and 4 patients respectively. Initial pathology was urothelial carcinoma; grade 2 in 6 patients and grade 3 in six patients.

Pathology from the subsequent surgery demonstrated urothelial carcinoma in the retained ureteral segment in 8 patients, dysplasia or atypia in 3 patients, and 1 patient with chronic inflammation. Local recurrence in 2 patients was present in a segment of ureter discontinuous with the bladder after laparoscopic nephroureterectomy. Three patients (25\%), all with initial grade 3 renal pelvis lesions, developed metastatic disease.

Conclusions: Tumor recurrence in a retained ureteral segment after incomplete nephroureterectomy is a significant problem and may contribute to intravesical recurrence or metastatic disease. Complete, en bloc resection is imperative to minimize these risks.
ARTICLE INFO

Key words:

Cystectomy; Carcinoma, Transitional Cell; Outcome Assessment (Health Care); Pathologic Processes

Int Braz J Urol. 2013; 39: 817-22

Submitted for publication: June 06, 2013

Accepted after revision:

September 17, 2013

\section{INTRODUCTION}

The gold standard for treatment of upper urinary tract urothelial carcinoma (utUC) is nephroureterectomy with excision of the entire ureter including the intramural segment and surrounding bladder cuff. The importance of excision of the entire ureter for utUC was recognized as early as 1934 with the observation that recurrence in the ureteral stump could be avoided if the entire ureter was excised. Over 70 years later, reports are still confirming the importance of complete ureteral excision with a high rate of local and metastatic tumor recurrence in patients who undergo incomplete ureterectomy (1). Ko et al. reported a surprisingly high rate $(10 \%)$ of incomplete ureterectomy. Despite multiple techniques for excision of the distal ureter and bladder cuff (2-6), the standard of care is 
the same: resection of the kidney and ureter with a margin of bladder cuff without tumor spillage. The purpose of our study was to evaluate the oncologic and pathologic outcomes following salvage distal ureterectomy for a retained ureteral segment after incomplete nephroureterectomy for utUC of the renal pelvis or upper ureter.

\section{MATERIALS AND METHODS}

Patients who underwent surgery for a retained ureteral segment after incomplete nephroureterectomy were identified from an institutional database and patient information was collected under an institutional review board approved protocol. For patients whose initial surgery was outside our institution, pathology was reviewed by a genitourinary pathologist at our institution. Stage was assigned according to the 2002 American Joint Committee on Cancer.

The surgical approach to nephroureterectomy was via an open approach prior to 1998 and later included both open and laparoscopic techniques. All distal ureterectomies were performed via an open approach.

\section{RESULTS}

From January 1993 to July 2007, 12 patients underwent surgical management of a retained ureteral segment after incomplete nephroureterectomy for utUC. Ten patients had nephroureterectomy at outside institutions and one patient had nephroureterectomy at our institution. Another patient underwent radical nephrectomy at our institution for a 9x6x6 cm upper pole renal mass presumed to be renal cell carcinoma which was diagnosed as urothelial carcinoma postoperatively.

There were ten male and two female patients and the median age of the cohort at the time of distal or segmental ureterectomy was 60.5 years (41-85 years). Pathologic characteristics for the cohort are shown in Table-1. Eleven patients were diagnosed with renal pelvic tumors prior to nephroureterectomy and the surgical approach for the initial surgery was open, laparoscopic, and hand-assisted laparoscopic in 9, 1, and 2 patients, respectively. Indication for completion ureterectomy was known recurrence in the retained ureteral segment (7), removal at time of cystectomy (3), unsuspected urothelial cancer in initial specimen (1), and completion of initial operation following nephrectomy with the unexpected finding of urothelial carcinoma (1).

The median time from nephroureterectomy to distal ureterectomy was 23.5 months (range 2-66). The median length of ureter removed at time of distal ureterectomy was $4.9 \mathrm{~cm}$ $(2.2-18.5 \mathrm{~cm})$. Eight patients had tumor within the retained ureter, three patients had low grade dysplasia or atypia, and one patient had chronic inflammation. The largest tumor in the retained ureter measured $4 \mathrm{~cm}(0-4 \mathrm{~cm})$.

Nine patients underwent a TUR for bladder cancer prior to distal ureterectomy. Of these, three patients underwent cystectomy at the time of distal ureterectomy and 1 patient underwent cystectomy for recurrent bladder cancer 3.5 years following the distal ureterectomy.

Two of the three patients that did not have bladder recurrences in the interval between nephroureterectomy and distal ureterectomy underwent distal ureterectomy at 2 and 7 months after nephroureterectomy; initial pathology was pT1G2 and pT3G3, respectively. The patient who underwent distal ureterectomy at two months was initially believed to have an upper pole renal cell carcinoma and the patient who underwent surgery at 7 months referred himself to our institution for distal ureterectomy after reviewing his own medical record.

Metastatic disease developed in 3 out of 6 (50\%) patients who initially presented with grade 3 tumors of the renal pelvis, all three patients have since expired. One of these patients had metastasis at the time of incomplete nephroureterectomy, but had a complete response to adjuvant chemotherapy, and underwent distal ureterectomy. He later developed diffuse metastatic disease and expired.

The median follow-up after distal ureterectomy for patients with initial grade 3 disease was 33 months (range 1-151). Patients with grade 3 renal pelvis lesions presented with higher initial stage than patients with grade 2 tumors (Table-1). Patients with an initial grade 3 renal pelvis lesion underwent distal ureterectomy sooner, at a median of 22.5 months versus 30.5 months for an initial grade 2 tumor. 
Table 1 - Twelve patients with retained ureteral segment.

\begin{tabular}{|c|c|c|c|c|c|c|c|}
\hline $\begin{array}{l}\text { Patient age } \\
\text { at time of } \\
\text { distal urete- } \\
\text { rectomy }\end{array}$ & $\begin{array}{l}\text { pStage at time } \\
\text { of nephro- } \\
\text {-ureterectomy }\end{array}$ & $\begin{array}{l}\text { Grade renal } \\
\text { pelvis lesion at } \\
\text { time of nephro- } \\
\text {-ureterectomy }\end{array}$ & $\begin{array}{l}\text { Time to } \\
\text { ureterectomy } \\
\text { (months) }\end{array}$ & $\begin{array}{l}\text { Ureter } \\
\text { pStage at } \\
\text { time of } \\
\text { salvage }\end{array}$ & $\begin{array}{l}\text { Grade of ureteral } \\
\text { lesion at time of } \\
\text { salvage }\end{array}$ & $\begin{array}{l}\text { Ureteral tumor } \\
\text { max dimension } \\
\quad(\mathrm{cm})\end{array}$ & $\begin{array}{l}\text { Length of ure- } \\
\text { ter remaining } \\
\qquad(\mathrm{cm})\end{array}$ \\
\hline 41 & pTa & 2 & 55 & pTa & 1 & 1.3 & 11 \\
\hline 50 & pTa & 2 & 9.5 & pT3 & 2 & $\mathrm{n} / \mathrm{a}$ & 4.2 \\
\hline 57 & pT1 & 2 & 46 & pTa & 2 & $\mathrm{n} / \mathrm{a}$ & $\mathrm{n} / \mathrm{a}$ \\
\hline 55 & $\mathrm{pT} 1$ & 2 & 15 & pT1 & 2 & 2 & 4.7 \\
\hline 64 & $\mathrm{pT} 1$ & 2 & 66 & pT0 & dysplasia & 0 & 10 \\
\hline 61 & pT1 & 2 & 2 & pT0 & atypia & 0 & 3.5 \\
\hline 85 & pTa & 3 & 32 & pT2 & 3 & $n / a$ & $n / a$ \\
\hline 73 & pT2 & 3 & 39 & pTO & $\begin{array}{c}\text { chronic } \\
\text { inflammation }\end{array}$ & 0 & $\mathrm{n} / \mathrm{a}$ \\
\hline 63 & $\mathrm{pT} 3 \mathrm{~b}, \mathrm{~N} 1, \mathrm{M} 1{ }^{1}$ & 3 & 11 & pTis & CIS & 0 & 18.5 \\
\hline 69 & pT3 & 3 & 7 & pT0 & dysplasia & 0 & 5 \\
\hline 60 & pT3 & 3 & 50 & pT4a & 3 & 4 & $n / a$ \\
\hline 59 & pT3 & 3 & 13 & pTa & 3 & 1 & 2.2 \\
\hline
\end{tabular}

${ }^{1}$ All others presumed N0, M0

2extra-mural ureteral length

$\mathrm{n} / \mathrm{a}=$ information not available

$\mathrm{CIS}=$ carcinoma in - situ

pStage $=$ pathologic stage

There was no upgrading of disease between nephroureterectomy and distal or segmental ureterectomy. No patient with an initial Grade 2 renal pelvis lesion has died of disease regardless of findings at time of distal or segmental ureterectomy, including a patient one year after surgery for a pT3 ureteral lesion in a retained segment of ureter (Figures $1 \mathrm{a}, \mathrm{b})$. The tumor was discovered during routine CT surveillance. No ureteral orifice ipsilateral to the side of nephroureterectomy was identified on cystoscopy. Intra-operative and pathologic findings revealed an isolated segment of ureter with tumor distinct from the bladder. This patient had undergone a hand assisted laparoscopic nephroureterectomy.

None of the six patients with the longest delay in completion ureterectomy (median 48 mo. [range 32-66]) died of urothelial cancer at a median follow-up of 48 months (range 1-151) after distal ureterectomy (Table-2).

\section{DISCUSSION}

In patients with isolated ureteral cancers, there is evidence to suggest equivalent outcomes with segmental ureterectomy compared to nephroureterectomy $(7,8)$ although radical nephroureterectomy with bladder cuff removal remains the gold standard for patients with upper tract urothelial cancers (9). Patients with incomplete nephroureterectomy are at increased risk for bladder cancer and potentially decreased survival. The three deaths in this series occurred in patients with pT3G3 utUC. All underwent distal ureterectomy after adjuvant chemotherapy within one year of incomplete ne- 
Figure 1 - A) Isolated segment of left ureter with tumor $1.5 \mathrm{~cm}$ above the ureterovesical junction, B) At the ureterovesical junction the left ureter is not visible.

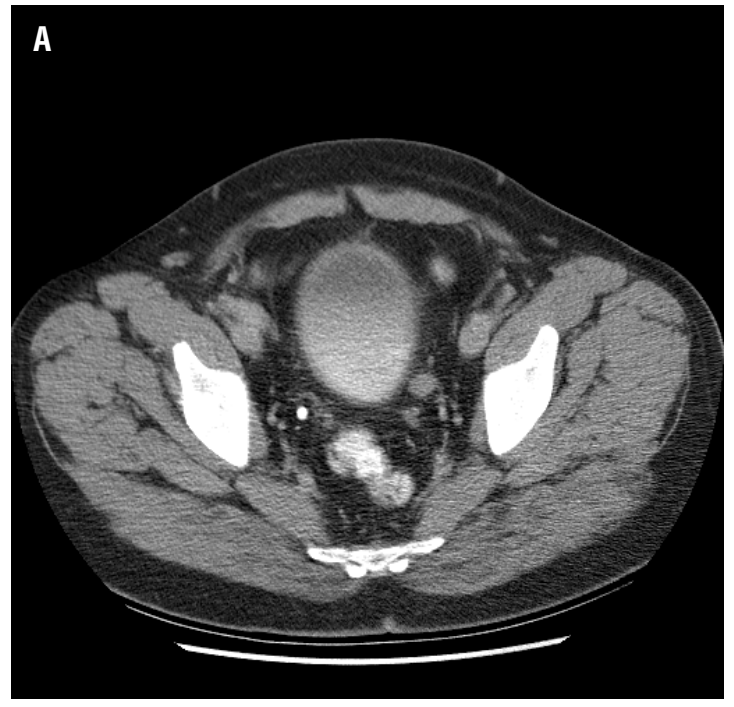

phroureterectomy. One patient who developed loco-regional disease recurrence and later underwent cystectomy with distal ureterectomy and retroperitoneal lymph node dissection has not had a recurrence. Whether these outcomes reflect the influence of tumor biology is unclear, and it is hazardous to extrapolate the data to the entire population of patients undergoing nephroureterectomy.

The question of whether the primary utUC lesion or the retained distal ureteral lesion sub-

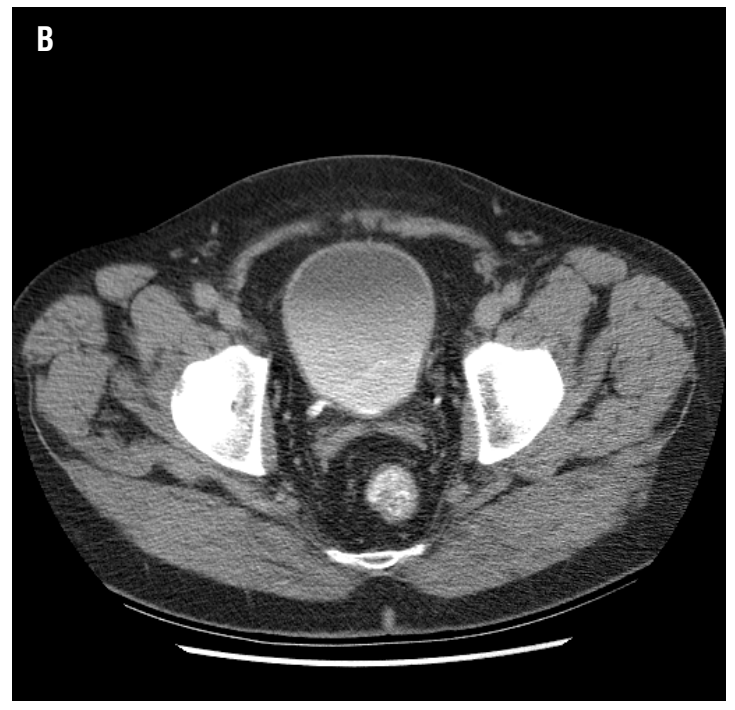

sequently leads to metastatic disease is difficult to answer. Ko et. al. (1) found that $60 \%$ (3/5) of patients with incomplete ureterectomy developed metastatic disease at a median of 10 months post-operatively. The authors concluded that incomplete ureterectomy not only leads to higher bladder cancer recurrence, but is often associated with the development of metastatic disease. Several other series have reported tumor rates in the retained ureteral stump from 30-60\% (10-13).

Table 2 - Patients who had delayed ureterectomy.

\begin{tabular}{lcccccc}
\hline $\begin{array}{l}\text { Difference in } \\
\text { surgery time } \\
\text { (months) }\end{array}$ & $\begin{array}{c}\text { Cystectomy } \\
\text { with distal } \\
\text { ureterectomy }\end{array}$ & $\begin{array}{c}\text { pStage at nephro- } \\
\text {-ureterectomy }\end{array}$ & $\begin{array}{c}\text { pStage } \\
\text { bladder }\end{array}$ & $\begin{array}{c}\text { Grade of renal pelvis } \\
\text { lesion at time of } \\
\text { nephro-ureterectomy }\end{array}$ & $\begin{array}{c}\text { Ureter stage } \\
\text { at time of } \\
\text { salvage }\end{array}$ & $\begin{array}{c}\text { Grade of ureteral } \\
\text { lesion at time of } \\
\text { salvage }\end{array}$ \\
\hline 55 & no & pTa & $\mathrm{pTa}^{*}$ & 2 & pTa & 1 \\
66 & yes & pT1 & pT0 & 2 & dysplasia & 0 \\
46 & yes & pT1 & pTa & 2 & pTa & 2 \\
32 & no & pTa & pT1 & 3 & pT2 & 3 \\
39 & no & pT2 & n/a* & 3 & chronic in- & 0 \\
50 & yes & pT3 & pT4ammation & pT4 & 3 \\
\hline
\end{tabular}

* Transurethral resection for staging, others staged at time of cystectomy 
Multifocality is seen in about 30\% of cases, and distal ureteral disease may be difficult to recognize (14). In patients with isolated ureteral cancers, there is evidence to suggest equivalent outcomes with segmental ureterectomy compared to nephroureterectomy $(7,8)$ although radical nephroureterectomy with bladder cuff removal remains the gold standard (9).

The majority of the patients in our series were referred due to recurrent bladder tumors. Although it is known that bladder cancer occurs after nephroureterectomy we suspect that patients with a tumor in a retained ureter may be more likely to have a bladder cancer occurrence. Nine of the twelve (75\%) patients developed urothelial cancer in the bladder after incomplete nephroureterectomy. This 75\% rate of bladder cancer is substantially higher than the reported literature for patients undergoing treatment for utUC $(1,11,15)$. Other factors including longer operative time (16) and longer length of follow-up $(7,17)$ are associated with higher rates of bladder cancer. We postulate that seeding from the upper tract may increase the rate of bladder cancer above the already significant baseline rate in these patients.

There are several limitations to this retrospective study. In addition to patients from our region, our practice includes many international and national referrals so it is difficult to accurately estimate incidence based on these findings. The majority of our patients were referred following recurrence of disease in the bladder. We believe this enabled us to find a high rate of tumors in the retained ureteral stump even when the ureter was discontinuous with the bladder. However, this study may not have found all patients with a retained ureteral stump, and we are missing the "denominator" of cases, since most were referrals. The follow-up of patients was not protocol based and varied between our institution and outside centers. utUC is a rare cancer and the finding of a retained ureteral stump after nephroureterectomy is even more rare, which limits the study size.

Minimally invasive surgical techniques have enabled radical nephroureterectomy to be accomplished through small incisions and with less postoperative pain. However, the distal ureterectomy rarely recapitulates the open approach. Multiple techniques are described for the minimally invasive excision of the distal ureter and a bladder cuff (2-6). Unfortunately, many techniques ligate the ureter extravesically and several centimeters of intravesical ureter may remain, which may develop into malignancy (18). A study by Matin and Gill (19) demonstrated the higher positive surgical margin rate, reduced bladder cancer recurrence free survival, and reduced overall survival when using extravesical laparoscopic stapling. The potential for viable cells between staple lines raises additional concerns with the laparoscopic stapling technique (20). Two of the patients in this series had retained ureteral tissue with tumor after laparoscopic stapling (2.2 $\mathrm{cm}$ in one and a small segment adjacent to the bladder in another). Residual segments of ureter containing tumor which are discontinuous with the bladder are also possible depending on technique and must be carefully evaluated with a high clinical index of suspicion (21). The current practice at our institution is to completely excise the distal ureter with a bladder cuff through a separate lower midline or Gibson incision when minimally invasive techniques are used.

It is noteworthy that most of the cases in the current study were associated with an open surgical approach for nephroureterectomy. Knowledge of the extent of the intravesical segment of ureter is essential for improving outcomes. This disease is too rare to allow for randomized studies to be conducted or for single institutional advances in technique to perform enough volume to establish safety. It is apparent from the collective data that utUC, and particularly high grade utUC, is an unforgiving disease that will take advantage of any disruption in oncologic principles.

\section{CONCLUSIONS}

Tumor recurrence in retained ureteral segments after incomplete nephroureterectomy is a significant and persistent problem and may increase bladder cancer occurrence. Complete, en bloc resection of the distal ureter with a cuff during nephroureterectomy is necessary. 


\section{ABBREVIATIONS}

utUC = upper urinary tract urothelial carcinoma

UC = urothelial carcinoma (formerly transitional cell carcinoma)

Mo. $=$ months

$\mathrm{cm}=$ centimeters

\section{CONFLICT OF INTEREST}

None declared.

\section{REFERENCES}

1. Ko R, Chew BH, Hickling DR, Razvi H, Luke PP, Chin JL, et al.: Transitional-cell carcinoma recurrence rate after nephroureterectomy in patients who undergo open excision of bladdercuff $v$ transurethral incision of the ureteral orifice. J Endourol. 2007; 21: 730-4.

2. Seifman BD, Montie JE, Wolf JS Jr.: Prospective comparison between hand-assisted laparoscopic and open surgical nephroureterectomy for urothelial cellcarcinoma. Urology. 2001; 57: 133-7.

3. Steinberg JR, Matin SF: Laparoscopic radical nephroureterectomy: dilemma of the distal ureter. Curr Opin Urol. 2004; 14: $61-5$.

4. Vardi IY, Stern JA, Gonzalez CM, Kimm SY, Nadler RB: Novel technique for management of distal ureter and en block resection of bladder cuff during hand-assisted laparoscopicnephroureterectomy. Urology. 2006; 67: 89-92.

5. Gonzalez CM, Batler RA, Schoor RA, Hairston JC, Nadler RB: A novel endoscopic approach towards resection of the distal ureter with surrounding bladder cuff during hand assistedlaparoscopic nephroureterectomy. J Urol. 2001; 165: 483-5.

6. Hu JC, Silletti JP, Williams SB: Initial experience with robotassisted minimally-invasive nephroureterectomy. J Endourol. 2008; 22: 699-704.

7. Bagrodia A, Kuehhas FE, Gayed BA, Wood CG, Raman JD, Kapur $\mathrm{P}$, et al.: Comparative analysis of oncologic outcomes of partial ureterectomy vs radical nephroureterectomy in upper tract urothelialcarcinoma. Urology. 2013; 81: 972-7.

8. Jeldres C, Lughezzani G, Sun M, Isbarn H, Shariat SF, Budaus $L$, et al.: Segmental ureterectomy can safely be performed in patients with transitional cell carcinoma of the ureter. J Urol. 2010; 183: 1324-9.

9. Colin P, Ouzzane A, Pignot G, Ravier E, Crouzet S, Ariane MM, et al.: Comparison of oncological outcomes after segmental ureterectomy or radical nephroureterectomy in urothelial carcinomasof the upper urinary tract: results from a large French multicentre study. BJU Int. 2012; 110: 1134-41.
10. Tan BJ, Ost MC, Lee BR: Laparoscopic nephroureterectomy with bladder-cuff resection: techniques and outcomes. J Endourol. 2005; 19: 664-76.

11. Strong DW, Pearse HD: Recurrent urothelial tumors following surgery for transitional cell carcinoma of the upper urinary tract. Cancer. 1976; 38: 2173-83.

12. Murphy DM, Zincke H, Furlow WL: Primary grade 1 transitional cell carcinoma of the renal pelvis and ureter. J Urol. 1980; 123: 629-31.

13. Murphy DM, Zincke H, Furlow WL: Management of high grade transitional cell cancer of the upper urinary tract. J Urol. 1981; 125: 25-9.

14. Brown GA, Busby JE, Wood CG, Pisters LL, Dinney CP, Swanson DA, et al.: Nephroureterectomy for treating upper urinary tract transitional cell carcinoma: Time to change the treatment paradigm? BJU Int. 2006; 98: 1176-80.

15. Krogh J, Kvist E, Rye B: Transitional cell carcinoma of the upper urinary tract: prognostic variables and post-operative recurrences. Br J Urol. 1991; 67: 32-6.

16. Kume H, Teramoto S, Tomita K, Nishimatsu H, Takahashi $\mathrm{S}$, Takeuchi T, et al.: Bladder recurrence of upper urinary tract cancer after laparoscopic surgery. J Surg Oncol. 2006; 93: 318-22.

17. Shalhav AL, Dunn MD, Portis AJ, Elbahnasy AM, McDougall EM, Clayman RV: Laparoscopic nephroureterectomy for upper tract transitional cell cancer: the Washington University experience. J Urol. 2000; 163: 1100-4

18. Bourdoumis A, Syed I, Soosay G, Manzoor A, Barua J: Transitional cell carcinoma of the ureteric stump: a systematic review of the literature. Urol Int. 2013; 91: 170-4.

19. Matin SF, Gill IS: Recurrence and survival following laparoscopic radical nephroureterectomy with various forms of bladder cuff control. J Urol. 2005; 173: 395-400.

20. Venkatesh R, Rehman J, Landman J, Lee D, Ragab ME, Sundaram CP, et al:: Determination of cell viability after laparoscopic tissue stapling in a porcine model. J Endourol. 2005; 19: 744-7.

21. Kim YJ, Jeon SH, Huh JS, Chang SG: Long-term follow-up of ureteral stump tumors after nephrectomy for benign renal disease. Eur Urol. 2004; 46: 748-52.

Correspondence address:

E. Jason Abel, MD

Assistant Professor of Urologic Oncology, Department of Urology

University of Wisconsin School of Medicine and Public Health 1685 Highland Avenue

Madison, WI, 53705-2281, USA Fax: + 1608 262-6453

E-mail abel@urology.wisc.edu 